DOI: $10.1002 /$ srin.201600111

Article type: Full Paper

\title{
The influence of microstructure and non-metallic inclusions on the machinability of clean steels
}

Niclas Ånmark, * Andrey Karasev, Pär Göran Jönsson

N. Ånmark, Dr. A. Karasev, Prof. P.G. Jönsson.

Department of Materials Science and Engineering, KTH Royal Institute of Technology, Brinellvägen 23, 10044 Stockholm, Sweden

E-mail: anmark@kth.se, karasev@kth.se,parj@kth.se

Keywords: carburising steel, grain size, non-metallic inclusions, machinability

\begin{abstract}
This study focused on the evaluation of the machinability of different carburising steel grades by using a cemented carbide cutting tool during semi finishing of steel. The effect of the steel composition, microstructure and inclusion characteristics on the cutting tool wear in the soft part turning was evaluated for a reference steel $\mathrm{R}(0.028 \% \mathrm{~S}, 0.0009 \% \mathrm{O})$, a clean $\mathrm{C}$ steel $(0.003 \% \mathrm{~S}, 0.0005 \% \mathrm{O})$, and an UC ultra clean steel $(0.002 \% \mathrm{~S}, 0.0004 \% \mathrm{O})$. An improved cutting tool life of about $10-25 \%$ was obtained when machining the reference steel $\mathrm{R}$. The favorable machining performance of this steel was attributed to its higher content of non-metallic inclusions, larger grain size and lower micro hardness than that of the clean steels.
\end{abstract}

\section{Introduction}

The level of a steels' cleanliness can be defined by its content of harmful elements i.e. the oxygen, sulfur, nitrogen, carbon, phosphorus and hydrogen contents. ${ }^{[1]}$ Holappa et al. reported that advances in steel manufacturing since the 1970's have resulted in new clean steel grades that contain less than $10 \mathrm{ppm}$ of impurities and that have an excellent mechanical strength and an excellent corrosion resistance. ${ }^{[1,2]}$ The driving force behind these advances comes partly from the automotive sector and partly from the oil and gas industry. Specifically they have demanded steel grades that can tolerate a high mechanical load or an aggressive and corrosive environment, respectively. In contrast to the excellent mechanical properties and/or corrosive resistance of ultra-clean steels, they are typically considered to be difficult to machine, which will result in a reduced cutting tool life. Therefore, the challenge of future steel technology is to produce high performance steel grades with an improved combined mechanical strength and machinability. ${ }^{[3]}$

Machinability itself is a wide and complex concept that indicates the overall machining performance of a workpiece. A machinability index is a general measure of a number of parameters, such as the power consumption, generated surface roughness of the machined workpiece, the ability to form chips, a cutting tool wear and an environmental impact. ${ }^{[4]}$ Therefore, the machinability index depends on the characteristics of the workpiece material, the cutting tool and the machining process. ${ }^{[5]}$ 
Carburising steel grades which are composed of about $0.2 \%$ carbon are common in automotive production. They are easy to machine for a soft condition (about 150-200 HB) and they offer a combination of a high mechanical strength and a high wear resistance for a hard condition (58-63 HRC). In addition, the characteristics of these steel grades can be modified by using a heat treatment operation, such as annealing, aging, quenching and tempering. ${ }^{[6]}$

Spheroidisation is a soft annealing process that occurs at an elevated temperature of about $950 \mathrm{~K}$, where the lamellar cementite $\left(\mathrm{Fe}_{3} \mathrm{C}\right)$ in the hard and brittle pearlite structure breaks into smaller fragments of a spherical shape, and moves to the softer ferrite phase. ${ }^{[7]}$ The purpose of a spheroidisation is to increase the formability and to reduce the hardness of the workpiece. ${ }^{[7,8]}$ Thus, a heat treatment operation is suitable to obtain an improved machinability of a carburising steel grade for a soft condition. Carburising itself gives a hard outer layer of about 1-1.5 mm thickness and a hardness of $60 \pm 2 \mathrm{HRC}$ which is necessary in industrial applications where the contact fatigue is a challenge such as in transmission components.

A comparison of the machinability between a standard carburising steel grade $(\mathrm{R}, 0.041 \% \mathrm{~S})$, a clean and an ultra-clean steel (C and UC, $0.001-0.004 \% \mathrm{~S}$ ) showed that the cutting tool life in hard part turning of the $\mathrm{R}$ steel was about $30 \%$ higher in comparison to the clean steels. ${ }^{[9]}$ However, no clear correlations between the machinability ratings of the standard and ultra-clean carburising steel grades and their content of non-metallic inclusions have yet been established for soft machining operations. Therefore, this study aims at clarifying the influence of steel cleanliness, inclusion characteristics and microstructure of spheroidised carburising steels on tool wear for soft part turning.

\section{Experimental}

\subsection{Workpiece material}

Three carburising steels provided by Ovako Hofors were investigated in this work. Their batch compositions, the corresponding ISO codes and the designations used in this study are presented in Table 1.

Table 1. Chemical composition of carburising steels used for the material analysis and machining tests (in wt-\%).

\begin{tabular}{lllllllllll}
\hline \multicolumn{2}{l}{ Steel grade ISO } & $\mathrm{C}$ & $\mathrm{Si}$ & $\mathrm{Mn}$ & $\mathrm{Cr}$ & $\mathrm{Ni}$ & $\mathrm{Mo}$ & $\mathrm{S}$ & $\mathrm{O}$ & $\mathrm{Ca}$ \\
\hline $\mathrm{R}$ & 20NiCrMo2-2 & 0.21 & 0.24 & 0.88 & 0.56 & 0.50 & 0.21 & 0.028 & 0.0009 & 0.0002 \\
$\mathrm{C}$ & 20NiCrMo7 & 0.20 & 0.24 & 0.60 & 0.53 & 1.69 & 0.24 & 0.003 & 0.0005 & 0.0002 \\
$\mathrm{UC}^{*}$ & 16NiCr6-4 F & 0.17 & 0.32 & 0.78 & 1.13 & 1.35 & 0.09 & 0.002 & 0.0004 & 0.0010 \\
\hline
\end{tabular}

*Ca-treated to $10 \mathrm{ppm}$.

The reference steel grade $\mathrm{R}$ is a common quality of carburising steel (280 ppm S, 9 ppm O) in automotive applications, like transmission components of a gearbox. Steel grades C and UC correspond to a clean steel (30 ppm S, 5 ppm O) and high performance and ultra clean steel (20 ppm S, 4 ppm O), respectively. The grades $\mathrm{C}$ and UC are designed for elevated levels of fatigue strength in gears and bearings whilst the grade $\mathrm{R}$ is easier to machine as it contains a larger amount of $\mathrm{MnS}$ inclusions. Also, $\mathrm{MnS}$ inclusions elongate during hot-working in the rolling direction acting as stress raisers in the steel matrix. Thus, $\mathrm{MnS}$ inclusions reduces the transverse fatigue strength of the reference steel. These test bars with a $90 \mathrm{~mm}$ diameter and a $500 \mathrm{~mm}$ 
length from all steel grades were soft annealed (spheroidised) at $945 \mathrm{~K}$ for 15 hours.

\subsection{Characterisation of steels}

The microstructure analysis of the investigated steel grades was conducted by using samples which were cut out at the position of a half radius of the steel bars. The cross-section of each sample was wet ground, polished and etched with a $2 \%$ nital solution. Thereafter, a light optical microscope (LOM) and a LEO SUPRA 35 field emission gun (FEG) scanning electron microscope (SEM) equipped with an electron backscatter diffraction (EBSD) camera detector were used for further microstructure evaluation. The grain size and orientation of the microstructures were identified by using EBSD and using an inverse pole figure (IPF) mapping. In the IPF, the crystal planes are indexed and coloured on the basis of their position in the stereographic triangle. In addition, an extra high tension (EHT) of $5 \mathrm{kV}$, an aperture of $60 \mu \mathrm{m}$, a step size $0.5 \mu \mathrm{m}(1000 \mathrm{x}), 0.05 \mu \mathrm{m}(10000 \mathrm{x})$ and $4 \mathrm{x} 4$ binning were used. Also, hardness profiles of steel bars were obtained by using a standardised measurement (Vickers method) on the transverse section of the cut out pieces of the rolled bars.

The equivalent carbon content $(C E)$ was estimated by using the formula provided by IIW:

$C E=\% C+\left(\frac{\% M n}{6}\right)+\left(\frac{\% C r+\% M o+\% V}{5}\right)+\left(\frac{\% N i+\% C u}{15}\right)$

where $\% \mathrm{C}, \% \mathrm{Mn}, \% \mathrm{Cr}, \% \mathrm{Mo}, \% \mathrm{~V}, \% \mathrm{Ni}$ and $\% \mathrm{Cu}$ represents a steel grade's content of carbon, manganese, chromium, molybdenum, vanadium, nickel and copper, respectively, given in wt-\%. ${ }^{[10]}$ The equivalent carbon content is a parameter which is often used to predict the physical property of a steel grade such as the hardenability and weldability, when alloying elements other than carbon are used. The idea is to convert the content of these alloying elements to their equivalent carbon percentage.

Non-metallic inclusions were studied in three dimensions (3D) after an electrolytic extraction (EE) and filtration of soft-annealed steel specimens. The steel specimens $(15 \times 10 \times 4 \mathrm{~mm})$ were cut out from the half radius of the steel bars in the longitudinal direction. The electrolytic extraction was conducted by using a 10\% AA electrolyte and an electrical current of 40-60 mA. Furthermore, the extracted non-metallic inclusions were collected during filtration on a polycarbonate filter with an open pore size of $0.4 \mu \mathrm{m}$. Then, the inclusions on the filter surface were investigated by using a SEM equipped with energy dispersive X-ray spectroscopy (EDS). The total amount of the analysed particles was 207, 119, and 70 for the grades R, C and UC, respectively. The characteristics of the observed inclusions were quantified with respect to length $(L)$, width $(W)$, shape (aspect ratio $A R=L / W)$, calculated equivalent diameter $\left(d_{e q}\right)$, number of inclusions per unit volume of steel $\left(N_{V}\right)$ and volume fraction of inclusions $\left(f_{V}\right)$. The $d_{e q}$ values were calculated by using the following equations:

$d_{e q}=\frac{L_{\max }+W_{\max }}{2}$ 
$N_{V}=n \cdot \frac{A_{f}}{A_{o b s}} \cdot \frac{\rho_{m}}{W_{d i s}}$

where $L_{\max }$ and $W_{\max }$ are the maximum length and maximum width of the analysed inclusion, respectively. The parameter $n$ is the number of observed inclusions in the selected size range, $\mathrm{A}_{f}$ is the area of film filter with inclusions after filtration and $\mathrm{A}_{\mathrm{obs}}$ is the total observed area. $\rho_{m}$ corresponds to the density of the sample metal matrix (equal to $\sim 0.0078 \mathrm{~g} \cdot \mathrm{mm}^{-3}$ ) and $W_{d i s}$ is the dissolved weight of steel during the extraction process.

\subsection{Machinability evaluation}

A commercial cemented carbide (CC) cutting tool of grade Sandvik GC4325 was used for the machinability tests of the steel bars. The cutting tool were positively shaped, had a nose angle

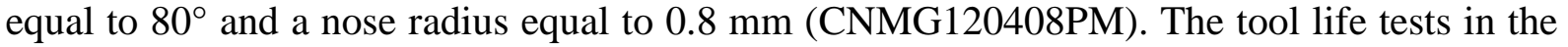
turning operation were performed by using the Walter C3-PCLNL-22040-12 holder and using a Castrol Syntilo 9913 coolant consisting of a 5\% emulsion (injected with a flow rate of $\left.2.4 \mathrm{~L} \cdot \mathrm{min}^{-1}\right){ }^{[11]}$ The main parameters used in the machining tests are given in Table 2.

Table 2. Main parameters for the machinability tests.

\begin{tabular}{ccccc}
\hline Machining test & Machining operation & Cutting speed, $v_{c}\left(\mathrm{~m} \cdot \mathrm{min}^{-1}\right)$ & Feed rate, $f_{n}\left(\mathrm{~mm} \cdot \mathrm{rev}^{-1}\right.$ & Depth of cut, $a_{p}(\mathrm{~mm})$ \\
\hline Tool life & Face turning & 300,360 and 450 & 0.3 & $2-3$
\end{tabular}

The test was considered ended when the cutting tool reached a maximum flank wear value $\left(V B_{\max }\right) \geq 0.3 \mathrm{~mm}$ or when it became damaged by an edge fracture, a chipping, a plastic deformation or a nose wear. The maximum flank wear $\left(V B_{\max }\right)$ of the cutting tools was measured at predetermined intervals by using LOM. Also, the tool wear analysis of the cutting tools was undertaken by using a JEOL JSM 7000F FEG-SEM equipped with a back-scatter (BS) detector.

\section{Results and Discussion}

\subsection{The effect of microstructure and hardness of steels on cutting tool life}

Based on the evaluation of the microstructure, it was found that the steel grades has a ferritic-pearlitic structure which contains spheroidised cementite along the ferrite grain boundaries (GB). Typical SEM-EBSD images of grains in the investigated steel grades after soft annealing are shown in Figure 1. In addition, the main characteristics of the investigated steel grades are given in Table 3. 


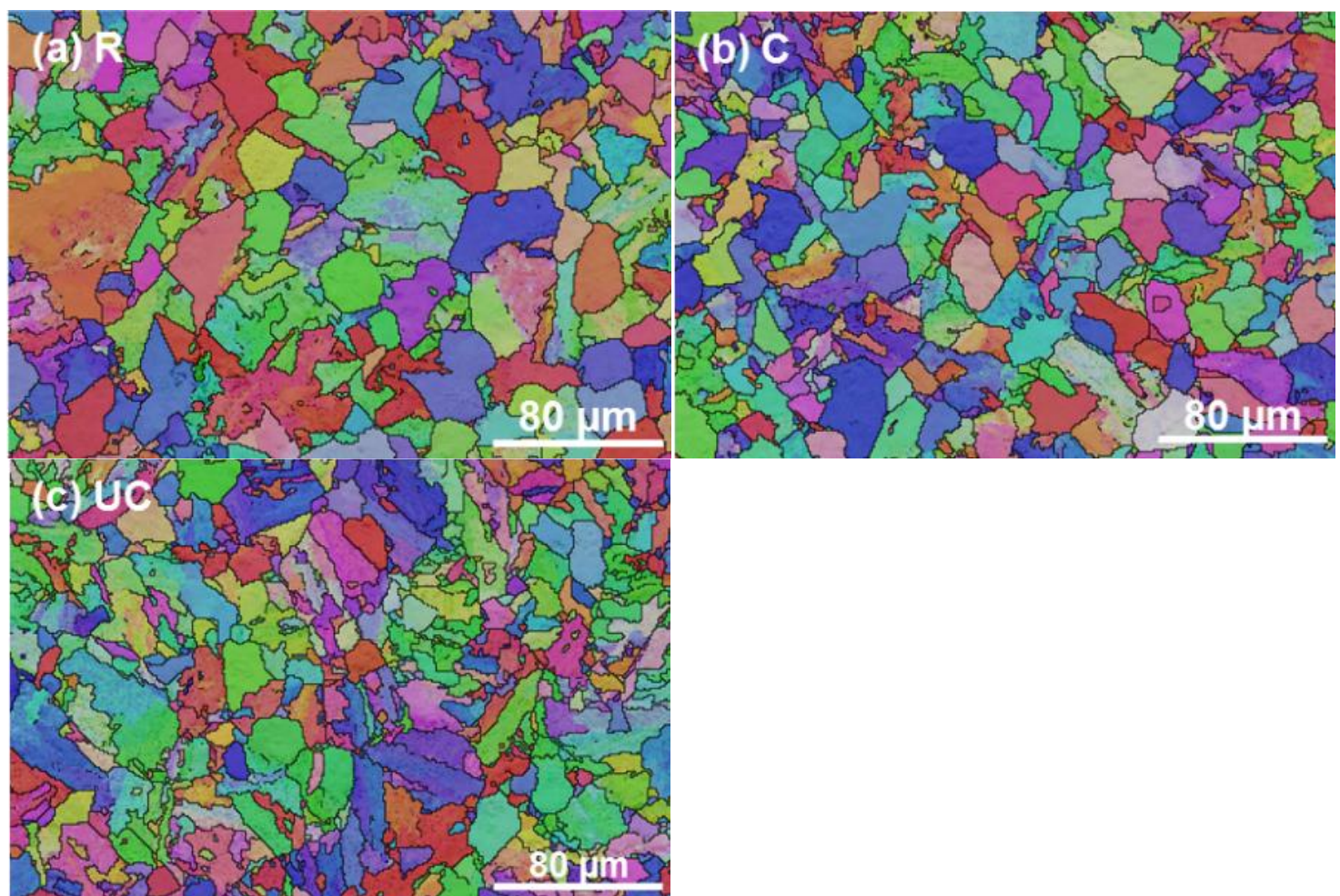

Figure 1. Orientation of grains in the investigated steel grades (a) R, (b), C (c) and UC.

Table 3. The microstructural characteristics of the investigated steel grades.

\begin{tabular}{cccccc}
\hline Steel & $\begin{array}{c}\text { Carbon content } \\
(\text { Wt- } \%)\end{array}$ & Microstructure & $\begin{array}{c}\text { Carbon equivalent, CE } \\
(\text { wt- } \%)\end{array}$ & $\begin{array}{c}\text { Average grain size, } D_{G} \\
(\mu \mathrm{m})\end{array}$ & $\begin{array}{c}\text { Hardness at 1/2 radius, } H V_{0.5 R} \\
(\mathrm{HV})\end{array}$ \\
\hline $\mathrm{R}$ & 0.21 & Ferrite-pearlite & 0.54 & $11.0 \pm 0.3$ & $149 \pm 4$ \\
$\mathrm{C}$ & 0.20 & Ferrite-pearlite & 0.57 & $9.4 \pm 0.5$ & $165 \pm 6$ \\
UC & 0.17 & Ferrite-pearlite & 0.63 & $8.2 \pm 0.3$ & $171 \pm 1$ \\
\hline
\end{tabular}

It is apparent that though the carbon content in the given steel grades decreases slightly, the carbon equivalent $(C E)$ and the average hardness of the steel bars $\left(H V_{0.5 R}\right)$ increases significantly. Also, the average grain size $\left(D_{G}\right)$ decreased in order from steel grade R to UC. Moreover, the relationships between the $C E, H V_{0.5 R}$ and $D_{G}$ values are shown in Figure 2a. The relative changes of the investigated characteristics of steel R, C and UC were evaluated by using the following equation:

$K\left(P_{i}\right)=\left(P_{i}\right) /\left(P_{R}\right)$

where $K\left(P_{i}\right)$ is the coefficient of relative change of parameter value $\left(P_{i}\right)$ for the $\mathrm{C}$ or UC steel grade in comparison to that for the reference $\mathrm{R}$ steel grade $\left(\mathrm{P}_{\mathrm{R}}\right)$. The obtained relationships between the values of $K(C E)$ and $K\left(P_{i}\right)$ are shown in Figure $\mathbf{2} \mathbf{b}$ for different steel grades. The parameter of $N_{A-G}$ in this figure corresponds to the number of grains per unit area observed on the surface of a metal sample. It can be seen that as the $C E$ value increased from 0.54 to 0.63 wt-\% (on 17\%) the $H V_{0.5 R}$ (on $15 \%$ ) and $N_{A-G}$ (on 97\%) values increased whilst the $D_{G}$ value decreased (on 25\%). It is interesting to point out that a change of the $C E$ value has a larger effect on the $N_{A-G}$ and $D_{G}$ values than on the $H V_{0.5 R}$ value. It means that the number of grains and the grain size of the investigated steel grades are strongly linked to the carbon equivalent. 
At the same time, the number of grains and the grain size of a steel grade are directly correlated to the surface area of grain boundaries. Consequently, the carbon equivalent has an influence on the surface area of grain boundaries within the steel matrix.
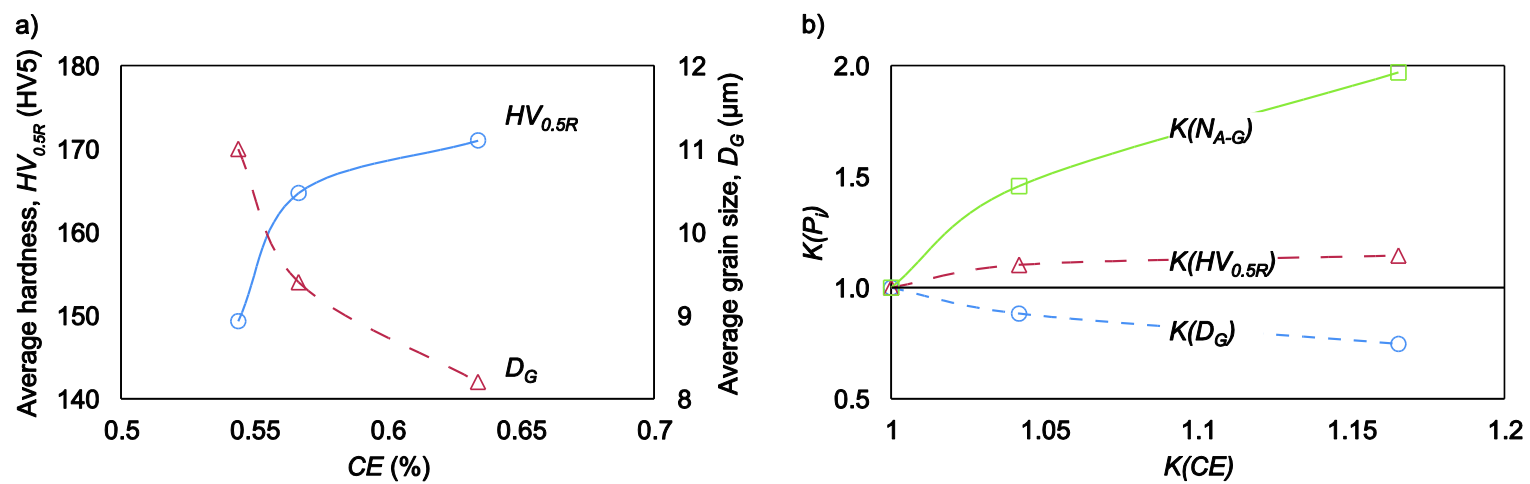

Figure 2. Relationships (a) between the $C E, H V_{0.5 R}$ and $D_{G}$ values and (b) between the coefficients of the relative change of the same parameters for the investigated steel grades.

It is known that a steel grade that has a higher equivalent carbon content has an improved hardenability, which corresponds to a higher hardness of the workpiece and, as a result, a reduced machinability. ${ }^{[12]}$ Furthermore, a steel grade that is characterised by a small average grain size has a high yield strength $\left(\sigma_{\mathrm{y}}\right)$, as is explained by the widely established Hall-Petch relation:

$\sigma_{y}=\sigma_{0}+k_{y} D_{G}^{-\frac{1}{2}}$

where $\sigma_{0}$ represents the contribution of friction-free stress from grain boundaries and $k_{y}$ is a material dependent constant whilst $D_{G}$ is the average grain size of the steel grade. As a result, steel grades with low $D_{G}$ values are expected to have a relatively poor machinability. It can be explained by the grain boundary strengthening, where the movement of the dislocations are hindered by the presence of grain boundaries. It results in a reduced mobility of the dislocations within the lattice structure and a higher onset point for plasticity. Thus, a higher critical stress is required to cause dislocation slip or a grain fracture. ${ }^{[13-16]}$ Moreover, steel grades with a small grain size have a larger area of grain boundaries. Therefore, they require a higher power consumption in metal cutting operations than steel grades with larger grains. These expectations were supported by the obtained tool life values of the steel grades R, C and UC at the different cutting speeds, which are shown in Figure 3. It should be pointed out that the largest effect of the metal matrix characteristics (such as $C E, H V_{0.5 R}, D_{G}$ and $N_{A-G}$ ) on the cutting tool life was obtained at the lower cutting speed. More specifically, the $T L$ value was increased with $24 \%$ at the cutting speed of $300 \mathrm{~m} / \mathrm{min}$ and only by $9 \%$ at a speed of $450 \mathrm{~m} / \mathrm{min}$. 
a)

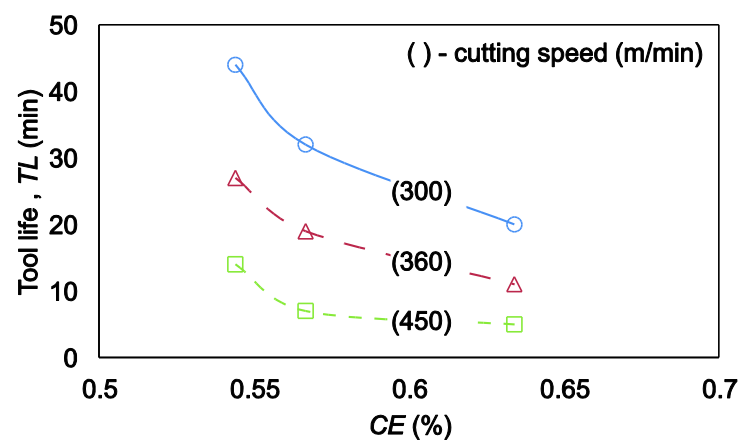

b)

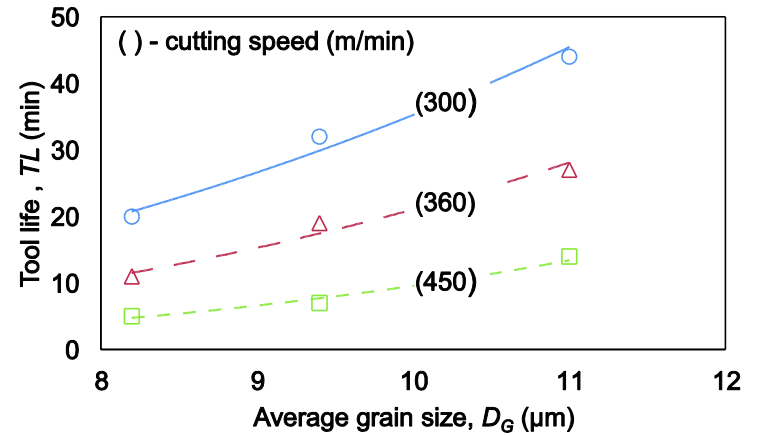

Figure 3. Cutting tool life of different carburising steel grades depending on the equivalent carbon content (a) and the average grain size (b).

\subsection{Inclusion characteristics of soft annealed carburising steels}

A comparison of the particle size distribution demonstrated differences between the steel grades (see Figure 4). The reference steel grade $\mathrm{R}$ contained a larger number of non-metallic inclusions than the clean steels $\mathrm{C}$ and UC. Grade R also contained the longest non-metallic inclusions. The majority of the non-metallic inclusions in this steel were elongated $\mathrm{MnS}$ with lengths of up to $145 \mu \mathrm{m}$. Also, a small amount of complex oxy-sulfides and oxides ( $\mathrm{Al}, \mathrm{Mg}) \mathrm{O}$ were found. Still, most of the non-metallic inclusions were not longer than $20 \mu \mathrm{m}$. A significantly smaller amount of non-metallic inclusions were found in the $\mathrm{C}$ and UC steel samples. Similarly to $\mathrm{R}$, the steel grade $\mathrm{C}$ contained mostly $\mathrm{MnS}$-rich inclusions and oxy-sulfides, even though a small number of pure oxides were found. On the contrary, the vast majority of the non-metallic inclusions in the ultra-clean steel (grade UC) consisted of CaS and complex oxy-sulfides. A small count of pure oxides was detected. The particles in grade UC were much smaller in size $(<10 \mu \mathrm{m})$ and more globular in shape. The main characteristics of non-metallic inclusions observed in steel samples from grade R, C and UC, after electrolytic extraction are given in Table 4.

a)

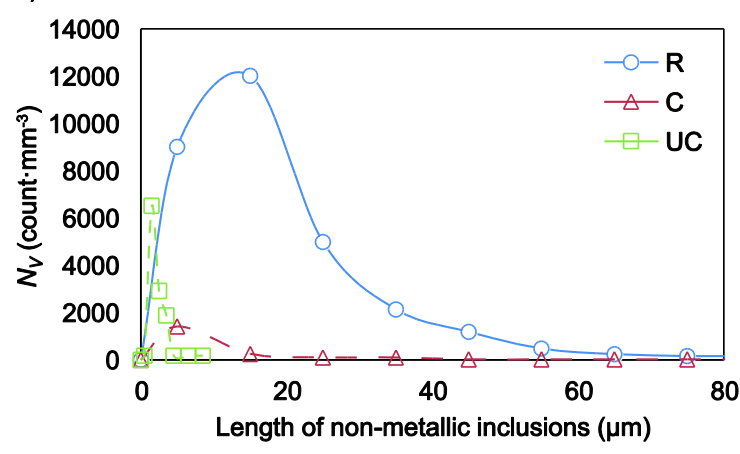

b)

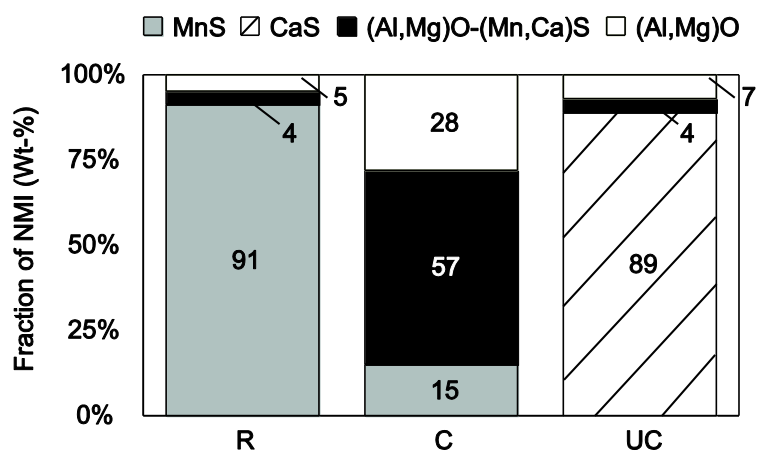

Figure 4. Particle size distributions (a) and the compositions of the non-metallic inclusions (b) observed in $\mathrm{R}, \mathrm{C}$ and UC steel grades.

Table 4. Characteristics of all non-metallic inclusions observed in different steel grades after EE*.

\begin{tabular}{cccccccc}
\hline $\begin{array}{c}\text { Steel } \\
\text { grade }\end{array}$ & $\begin{array}{c}\mathrm{S} \\
(\mathrm{wt}-\%)\end{array}$ & $\begin{array}{c}\mathrm{O} \\
(\mathrm{wt}-\%)\end{array}$ & $\begin{array}{c}L \\
(\mu \mathrm{m})\end{array}$ & $A R$ & $\begin{array}{c}d_{e q} \\
(\mu \mathrm{m})\end{array}$ & $\begin{array}{c}N_{V} \\
\left(\text { count } \cdot \mathrm{mm}^{-3}\right)\end{array}$ & $f_{V}$ \\
\hline $\mathrm{R}$ & 0.028 & 0.0009 & $19 \pm 17[2 \sim 145]$ & $10 \pm 7[2 \sim 33]$ & $5 \pm 3[1 \sim 23]$ & $3.10 \cdot 104$ & $3.60 \cdot 10-3$ \\
$\mathrm{C}$ & 0.003 & 0.0005 & $15 \pm 40[1 \sim 371]$ & $8 \pm 11[2 \sim 86]$ & $4 \pm 3[1 \sim 29]$ & $0.26 \cdot 104$ & $0.46 \cdot 10-3$ \\
UC & 0.002 & 0.0004 & $2 \pm 1[1 \sim 9]$ & $1 \pm 0.2[1 \sim 2]$ & $2 \pm 1[1 \sim 8]$ & $1.20 \cdot 104$ & $0.16 \cdot 10-3$ \\
\hline
\end{tabular}

*: [ ] - the minimum and maximum values of parameter. 
Typical SEM images of non-metallic inclusions observed in different steel grades are shown in Figure 5. The elongated $\mathrm{MnS}$ inclusions, the complex oxy-sulfides (contained ( $\mathrm{Al}, \mathrm{Mg}) \mathrm{O}$ core and $\mathrm{MnS}$ or $(\mathrm{Mn}, \mathrm{Ca}) \mathrm{S}$ outer layer) and globular $\mathrm{CaS}$ inclusions were observed in the samples.
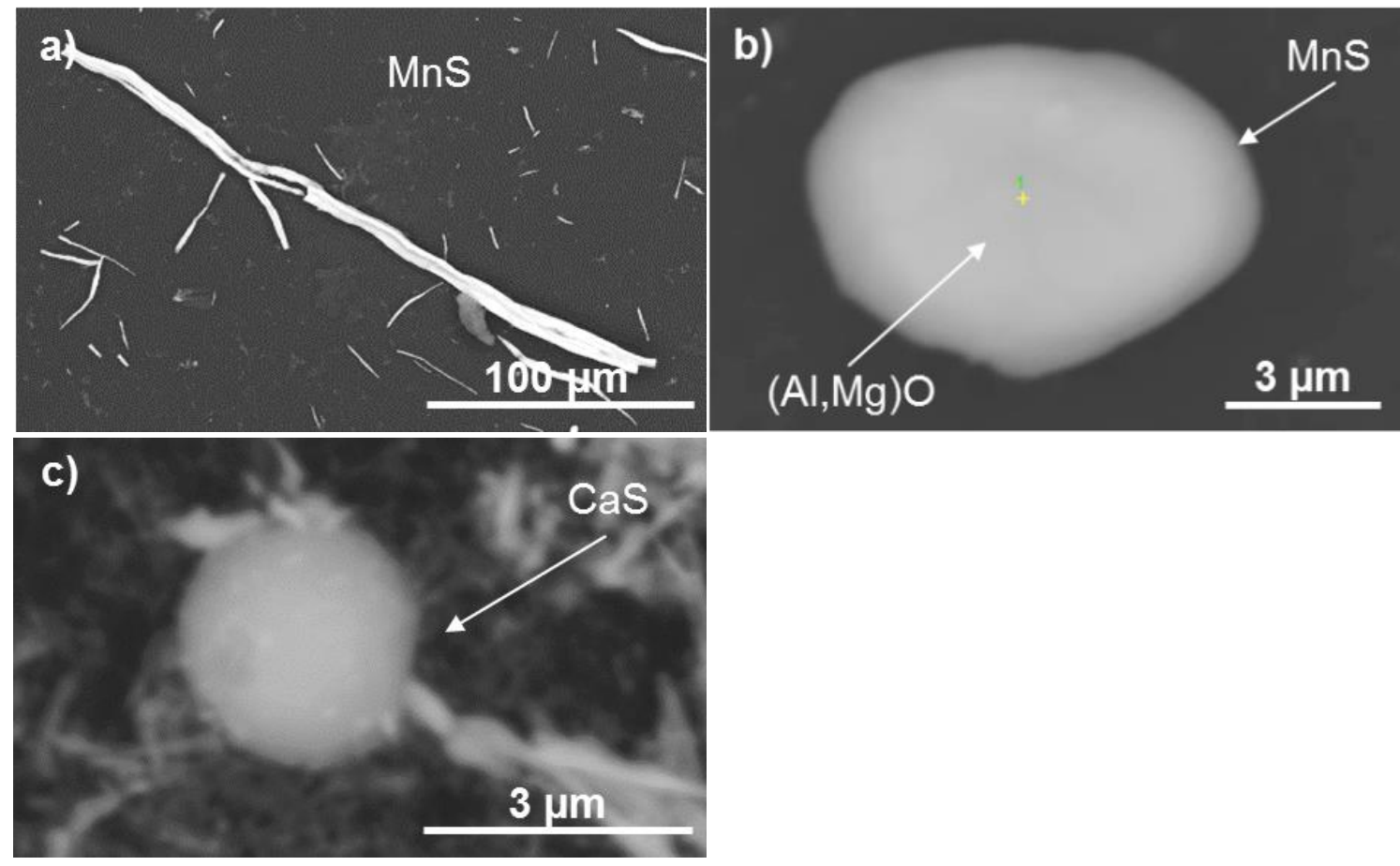

Figure 5. Typical SEM images of non-metallic inclusions observed in the R, C and UC steel grades after completed electrolytic extraction and filtration.

a)

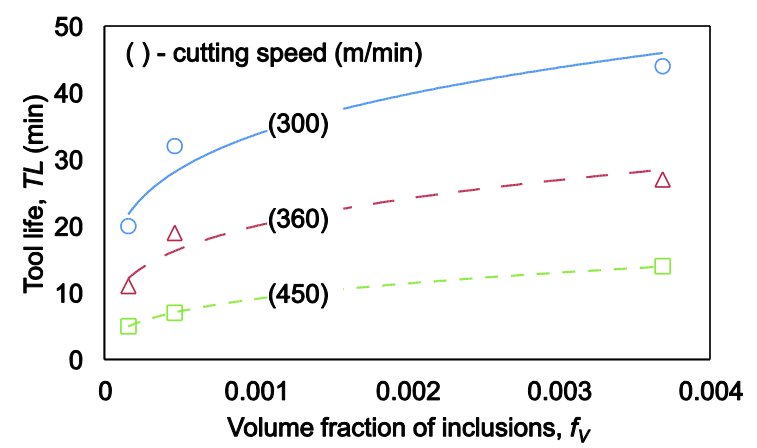

b)

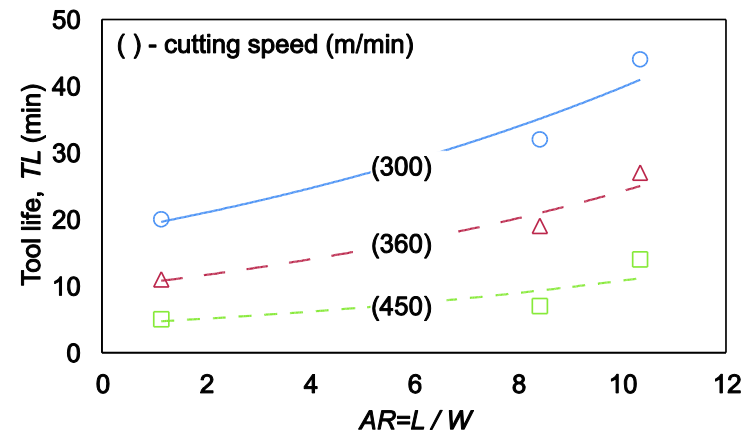

Figure 6. Cutting tool life $(T L)$ in soft part turning at different cutting speeds depending on (a) volume fraction $\left(f_{V}\right)$ and $(\mathrm{b})$ aspect ratio $(A R)$ of non-metallic inclusions in the given steel grades.

It can be seen in Figure 6 that the cutting tool life $(T L)$ in soft part turning depends on the volume fraction $\left(f_{V}\right)$ and aspect ratio $(A R=L / W)$ of non-metallic inclusions, and especially of $\mathrm{MnS}$-rich inclusions. More specifically, the larger values of $f_{V}$ and $A R$ of sulfide-rich inclusions promote an improved chip formation process and a reduced cutting tool wear. It can be explained by a significant increase of the surface area between the steel matrix and the nonmetallic inclusions. It is believed that a larger surface area can cause an easy exfoliation of the steel matrix along this interfacial surface. It should be pointed out that the aspect ratio of inclusions $(A R)$, which corresponds to their morphology, correlates to the surface area of inclusions in the steel. However, the volume fraction of inclusions $\left(f_{V}\right)$ characterizes the amount of non-metallic inclusions in the steel. Therefore, the effect of $f_{V}$ and $A R$ parameters on the tool 
life is shown in Figure 6 separately. Moreover, $\mathrm{MnS}$ inclusions are softer at machining temperatures than oxide inclusions. ${ }^{[5,17-18]}$ Therefore, $\mathrm{MnS}$ inclusions are less detrimental to the flank wear of a cutting tool. In addition, $\mathrm{MnS}$ inclusions promote the formation of protective slag deposits (often rich in calcium) on the cutting tool surface, which can reduce the flank and crater wear rate. ${ }^{[9,18-22]}$

\section{Conclusions}

The influence of the characteristics of metal matrix and non-metallic inclusions in steels on the tool wear for soft part turning of different spheroidised carburising steels ( $\mathrm{R}$ - common steel grade, $0.028 \% \mathrm{~S} ; \mathrm{C}-$ clean steel, $0.003 \% \mathrm{~S}$ and $\mathrm{UC}-$ ultra-clean steel, $0.002 \% \mathrm{~S}$ ) was investigated. Based on the results in the study, the following conclusions can be drawn:

1. An increased carbon equivalent $(C E)$ from $0.54 \mathrm{wt}-\%$ in the $\mathrm{R}$ steel to $0.63 \mathrm{wt}-\%$ in the UC steel promoted an increased average hardness by $15 \%$ at a half radius position of steel bars $\left(H V_{0.5 R}\right)$. In addition, when the number of grains per unit area observed on the surface of a metal sample $\left(N_{A-G}\right)$ increased by $97 \%$, the average grain size $\left(D_{G}\right)$ decreased by $25 \%$.

2. The cutting tool life (TL) increased with decreased $C E, H V_{0.5 R}$ and $N_{A-G}$ values and with increased $D_{G}$ values in the steel.

3. The largest effect of the metal matrix characteristics (such as $C E, H V_{0.5 R}, D_{G}$ and $N_{A-G}$ ) on the cutting tool life was obtained at the lower cutting speed. More specifically, the $T L$ value can be increased by $24 \%$ at a cutting speed of $300 \mathrm{~m} / \mathrm{min}$ and only by $9 \%$ at a speed of $450 \mathrm{~m} / \mathrm{min}$.

4. The soft part machinability of clean carburising steels (C and UC) is significantly improved by a resulfurisation (reference $\mathrm{R}$ ). The superior machinability of the standard steel grade $\mathrm{R}$ is partly linked to its high content of sulfur $(0.028 \mathrm{wt} \% \mathrm{~S})$, which results in an increased amount of $\mathrm{MnS}$ inclusions in the steel matrix. The MnS inclusions act as stress raisers in the primary shear zone during machining. As a result, they improve the chip formation process and prolong the cutting tool life.

\section{Acknowledgements}

This work was funded by the national strategic innovation program - national action for metallic materials, organised by Vinnova and Jernkontoret (Sweden). The research was conducted in collaboration between the participating companies and institutes, Ovako Hofors, Sandvik Materials Technology, Uddeholm Tooling, Sandvik Coromant, Outokumpu Stainless, Seco Tools, Swerea KIMAB and KTH Royal Institute of Technology.

Received: ((will be filled in by the editorial staff))

Revised: ((will be filled in by the editorial staff))

Published online: ((will be filled in by the editorial staff)) 


\section{References}

[1] L.E.K. Holappa, A.S. Helle, J. Mater. Process. Technol. 1995, 36, 177.

[2] R.V. Väinölä, L.E.K. Holappa, P.H.J. Karvonen, J. Mater. Process. Technol. 1995, 53, 453.

[3] N. Ånmark, Licentiate Thesis, KTH Royal Institute of Technology, Stockholm, Sweden, May, 2015.

[4] J.-E. Ståhl, Metal cutting - theories and models, Lund University, Lund, Sweden 2012.

[5] N. Ånmark, A. Karasev, P. Jönsson, Mater. 2015, 8, 751.

[6] T. Holm, P. Olsson, E. Troell, Steel and its Heat treatment, Swerea IVF, Gothenburg, Sweden 2012.

[7] N. Gupta, S.K. Sen, Def. Sci. J. 2006, 56, 665.

[8] D. Hauserova, J. Dlouhy, Z. Novy, Arch. Metall. Mater. 2014, 59, 1199.

[9] N. Ånmark, T. Björk, A. Ganea, P. Ölund, S. Hogmark, A. Karasev, P.G. Jönsson, Wear. 2015, 334-335, 13.

[10] J.F. Lancaster, Metallurgy of welding, Abington Publishing, Cambridge, UK 1999.

[11] SIS, SS-ISO 3685 Tool life testing with single-point turning tools. 1994.

[12] J.P. Davim, Machinability of Advanced Materials, Wiley, Somerset, USA 2014.

[13] A. Iza-Mendia, I. Gutiérrez, Mater. Sci. Eng. A. 2013, 561, 40.

[14] E.O. Hall, Phys. Soc. Sec. B. 1951, 64, 747.

[15] N.J. Petch, Acta Metall. 1987, 35, 2027.

[16] M.-Y. Seok et al. Scripta. Mater. 2014, 87, 49.

[17] C.-H. Leung, L. Van Vlack, J. Am. Cer. Soc. 1979, 62, 613.

[18] C.-H. Leung, L. Van Vlack, Metall. Trans. A. 1981, 12A, 987.

[19] D. Lou, K. Cui, Y. Jiang, J. Mater. Eng. Perform. 1997, 6, 215.

[20] L. Jiang, K. Cui, H. Hänninen, J. Mater. Process. Tech. 1996, 58, 160.

[21] E. Harju, S. Kivivuori, A.S. Korhonen, Surf. Coat.Tech. 1999, 112, 98.

[22] J.M. Brion, B. Sander, G. Pierson, Wear, 1992, 154, 225. 